\title{
3D FINITE ELEMENT METHOD MODELING AND SIMULATION OF THE TEMPERATURE OF CRYSTALLINE PHOTOVOLTAIC MODULE
}

\author{
Nyanor Peter', Oman Emmanuel Kabu², Kudadze Stephen ${ }^{3}$, Deku Anthony ${ }^{4}$ \\ ${ }^{1}$ Lecturer, Mechanical Engineering Department, Accra Polytechnics, Accra, Ghana \\ ${ }^{2}$ Senior Lecturer, Mechanical Engineering Department, Accra Polytechnics, Accra, Ghana \\ ${ }^{3}$ Senior Lecturer, Mechanical Engineering Department, Accra Polytechnics, Accra, Ghana \\ ${ }^{4}$ Lecturer, Mechanical Engineering Department, Accra Polytechnics, Accra, Ghana
}

\begin{abstract}
The temperature reached by solar cells/modules during operation has been simulated to have information about the temperature distribution in the solar cell/module. A finite element (FE) model of the solar cell/module was created in COMSOL Multiphysics environment. The simulations enable visualization of the temperature distribution in crystalline silicon solar cell. The effect of different encapsulating materials, Ethylene-vinyl Acetate (EVA) and silicone on cell temperature are also investigated. An unwanted side-effect of the encapsulation of solar cells into a PV module is that the encapsulation alters the heat flow into and out of the PV module, thereby increasing the operating temperature of the PV module. These increases in temperature have a major impact on the PV module by reducing its voltage, thereby lowering the output power. A finite element (FE) model representing a real crystalline silicon solar cell/module in terms of size, mechanical and material properties is created. An in-depth study of the FE software used, COMSOL Multiphysics is done in other to get the best output in terms of solver configuration and memory considerations. Four different geometries of the solar cell/module are created for these simulations; each representing a stage or variant in the solar module assembly. At first, the models are validated comparing results from simulations such as the effect of changes in solar irradiance, wind velocity and incident angle of solar irradiance on temperature with those in literature. The effect of the type of protective cover used in the encapsulation, either glass-glass or glass-Tedlar on cell temperature is analyzed. The thickness of the protective cover layers and its optical properties are also investigated based on their effects on cell/module temperature. All the simulations leading to the conclusions drawn about the cell/module temperature and its distribution were performed by varying wind velocity, irradiance, material sizes and incident angle among other model modifications. The color maps and graphs are presented in this study.
\end{abstract}

Key Words: Modeling, COMSOL Multipysics, Crystalline silicon solar cell/module, FE simulations, Temperature

\section{INTRODUCTION}

Solar energy provides a great potential as a renewable energy source. It is constantly improving and becoming a competitive energy source for the future. Recently, there has been an enormous increase in the understanding of the principle of operation of photovoltaic devices, which led to a rapid increase in the power conversion efficiencies of such devices. New methods of harnessing the full spectrum of the sun's wavelength and new materials for making solar cells are paving way for solar power to be the emerging power resource for the world at large.

A photovoltaic (PV) module exposed to sunlight generates heat as well as electricity. For a typical commercial PV module operating at its maximum power point, only 15 to $20 \%$ of the incident sunlight is converted into electricity [1], with much of the remainder being converted into heat. In dealing with solar module efficiency, one important effect to consider is the temperature of the module. According to the theory, the output power of a crystalline solar cell decreases by $0.4 \%$ when the temperature increase is equal to $1^{\circ} \mathrm{C}$ above the optimum operating temperature [2]. Thus a thorough understanding of the sources, distribution and values of temperature reached in operation by the solar module is of utmost importance. In addition, increases in temperature are implicated in several failure or degradation modes of PV modules, as elevated temperatures increase stresses associated with thermal expansion and also increase degradation rates by a factor of about two for each $10^{\circ} \mathrm{C}$ increase in temperature [1].

Solar cells are made from semiconductor materials that turn sunlight into electricity. This effect was first recorded by E. Becquerel, in 1839 [3]. In 1877 the first solid state device was recorded to show such an effect. However, it was in 1954 at Bell Labs when the solar electric effect was demonstrated in silicon ( $\mathrm{Si}$ ) that the idea of producing useable amounts of electricity from solar cells began.

\section{TEMPERATURE MODEL OF SOLAR}

CELL/MODULE IMPLEMENTED IN COMSOL MULTIPHYSICS ENVIRONMENT

To simulate the solar cell/module operating temperature, a model of the solar cell/module is created in COMSOL Multiphysics. The geometry needed for each simulation is created, the material properties are defined based on values 
from the COMSOL materials library and literature.

\subsection{Creating the geometry}

To simulate the solar cell/module operating temperature, a model of the solar cell/module is created in COMSOL Multiphysics. The geometry needed for each simulation is created, the material properties are defined based on values from the COMSOL materials library and literature

\subsubsection{Model A: Solar Cell Consisting Of Silicon,}

\section{Aluminum, Busbars And Fingers}

Model A Is A $12.5 \mathrm{Cm}$ X $12.5 \mathrm{~cm}$ solar cell consisting of the following layers from bottom to top: aluminum, silicon, busbars and fingers. The busbars and fingers are made of silver. This represents the basic components of the solar cell without the encapsulation and protective cover. The components and its arrangement are shown in Fig - 1 . The silicon is $300 \mu \mathrm{m}$ thick, aluminum is $30 \mu \mathrm{m}$ thick and the busbars and fingers are $18 \mu \mathrm{m}$ thick. The bus bars are 1.5 $\mathrm{mm}$ wide whiles the fingers are $250 \mu \mathrm{m}$ wide. There are two busbars and 30 fingers on the silicon surfaces. The fingers are the smallest in size and thus determine to a large extent the mesh size. The percentage coverage of the fingers on silicon surface of a solar cell is typically estimated to be between 7 and $9 \%$. The number of fingers was selected to be as close to reality (percentage coverage range) as possible and reduce computational cost to a minimum.

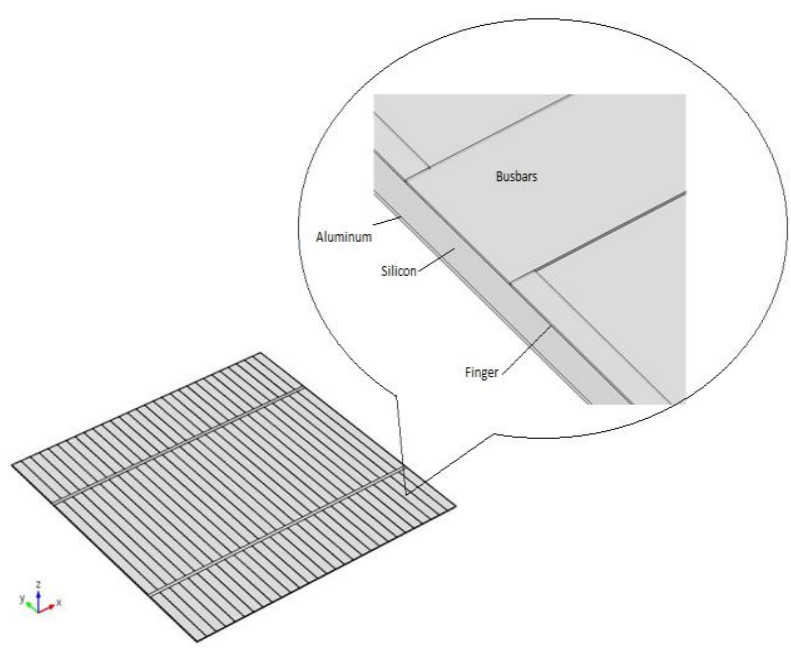

Fig -1: Model A - Solar cell consisting of silicon, aluminum, busbars and fingers

\subsubsection{Model B: Solar cell made up of Model A, Glass, EVA and Tedlar}

Model B is made up of Model A described in 2.1.1, laminated with a $450 \mu \mathrm{m}$ thick Ethylene-vinyl Acetate (EVA) on both sides, a protective solar glass $3.2 \mathrm{~mm}$ thick on the upper side and $500 \mu \mathrm{m}$ thick Tedlar protecting the back side. The layers are arranged as shown in Fig -2. The basic cell part (Model A) has the same configuration and is revealed in a transparent view (a view with glass, EVA and Tedlar shown as transparent) in Fig -3.

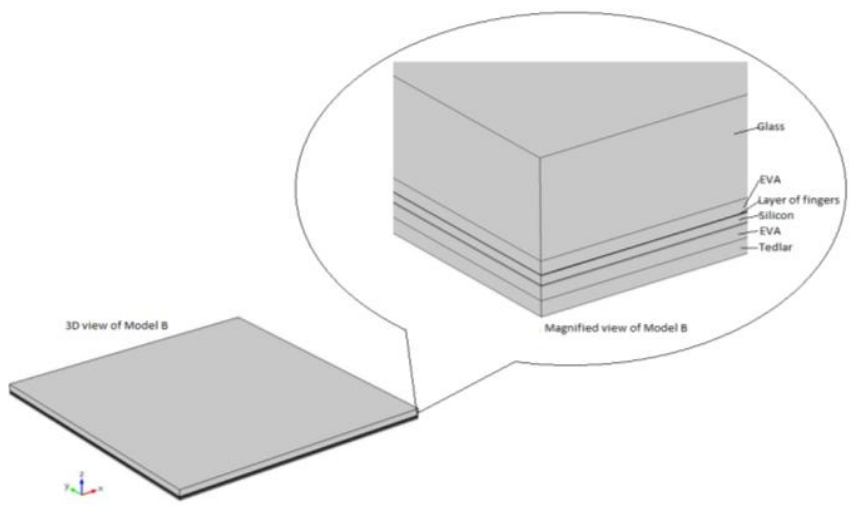

Fig -2: Model B - Solar cell made up of Model A, Glass, EVA and Tedlar

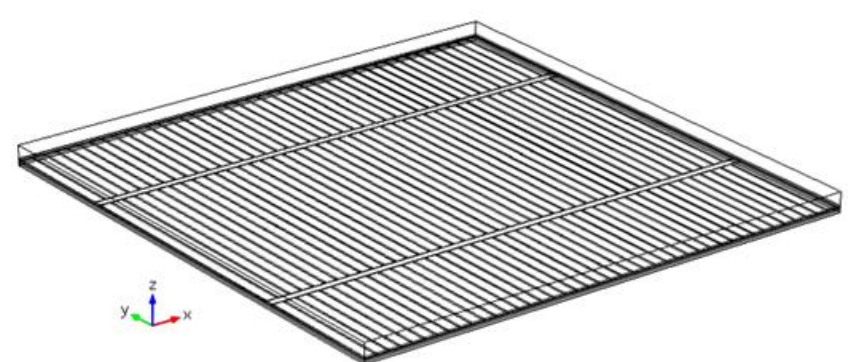

Fig -3: Transparent view of Model B revealing busbars and fingers arrangement.

Model B was used in the simulation to analyze the additional effect of encapsulation materials (Glass, EVA and Tedlar) on the cell temperature. The laminating material EVA is replaced by silicone, another laminating material, to ascertain if the increase in efficiency of the silicone laminated modules affects the cell operating temperature.

\subsubsection{Model C: Solar cell made up of Model A, glass, EVA}

Model C is made up of the same base as Model B but in this model, the protective back of Tedlar is substituted by glass. This model has top and bottom glass protective cover. Each glass layer is $3.2 \mathrm{~mm}$ thick.

The model is used to simulate the effect of having glass on both sides on cell temperature as compared to Tedlar on the back side. This model is shown both in $3 \mathrm{D}$ and as a transparent structure in Fig -4 and Fig -5, respectively.

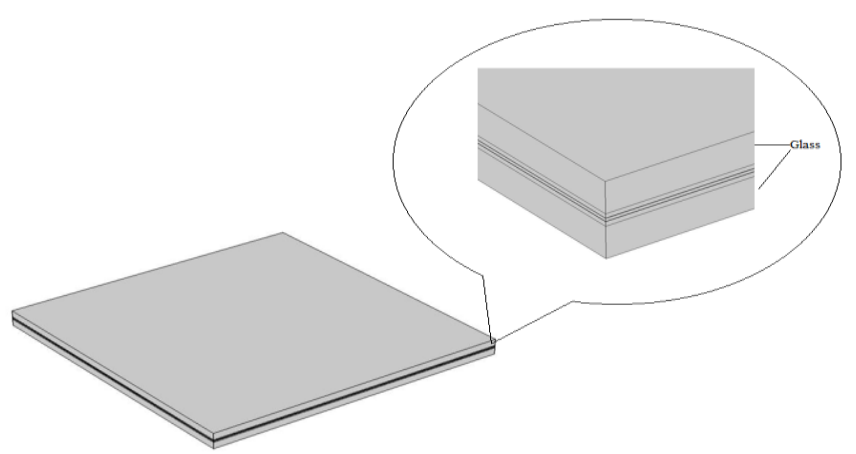

Fig -4: Model C: Solar cell made up of Model A, glass, EVA 


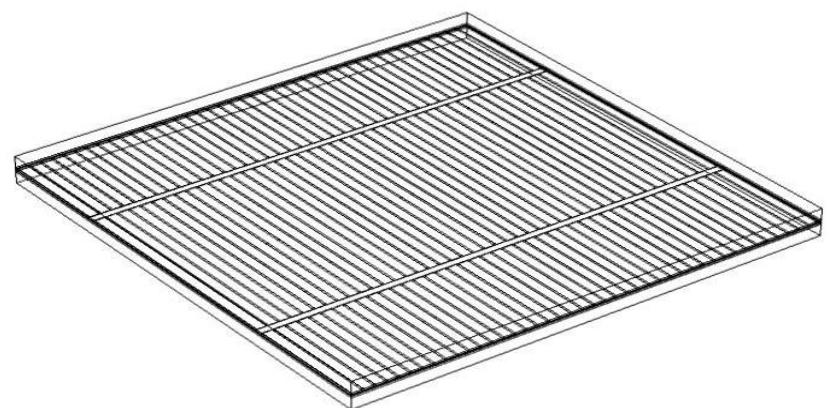

Fig -5: Transparent view of Model C revealing busbars and fingers

\subsubsection{Model D: Solar Module Made Up Of Two of}

\section{Model B With Copper Interconnection}

Model D is a two cell mini solar module. To conserve cumputer memory during computation and to take advantage of the symmetric nature of the geometry, only a quarter of each cell is used. The cells have the same structure and composition as the cell in Model B. The two quarter cells are connected with a copper stripe. The two cells are placed $7 \mathrm{~mm}$ apart and encapsulated with glass, EVA and Tedlar as in Model B. The entire space around the interconnecting copper stripe is filled with EVA. The 3D view as well as the transparent view of the model is shown in Fig -6 and Fig -7 respectively. The copper stripe is modeled here as a straight bar due to memory considerations. A symmetry boundary condition is defined on three sides of the mini module to form a complete twocell module.

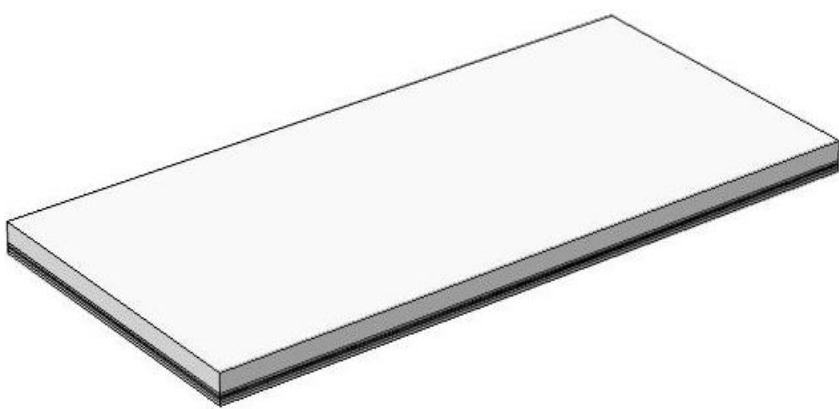

Fig -6: Model D: Solar module made up of two of Model B with copper interconnection

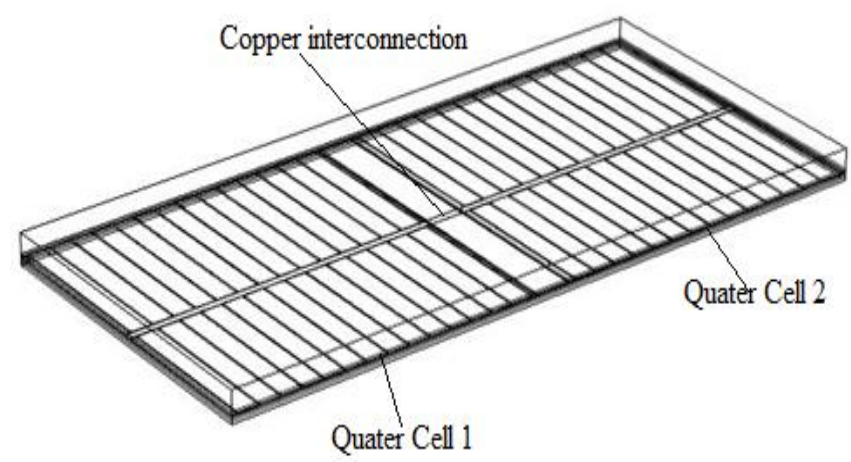

Fig -7: Transparent view of Model D showing the two cells and copper interconnections.
Model D is used for the simulation of the temperature distribution in the EVA surrounding the copper interconnections, the effect of copper on cell/module temperature as well as the effect of the distance between adjacent cells on temperature.

\subsection{Definition Of Material Properties}

The material properties were taken from literature as well as from the COMSOL material library. The following materials are used in the modeling: glass, EVA, silicone, silver, silicon, aluminum, Tedlar and copper.

Table -1: Sample material properties table [5] [6] [7] [8]

\begin{tabular}{|c|c|c|c|c|c|}
\hline $\begin{array}{l}\text { Material } \\
\text { Property } \\
\text { [Unit] }\end{array}$ & $\frac{n}{0}$ & $\gtrless_{i=1}^{\ll}$ & $\sum_{\overline{0}}^{\grave{D}}$ & $\stackrel{\Xi}{\stackrel{\circlearrowright}{0}}$ & $\stackrel{\Xi}{\Xi}$ \\
\hline $\begin{array}{l}\text { Density } \\
{\left[\mathrm{kg} / \mathrm{m}^{3}\right]}\end{array}$ & 2200 & 935 & 10500 & 2329.1 & 2700 \\
\hline $\begin{array}{l}\text { Thermal } \\
\text { conductivity } \\
{[\mathrm{W} /(\mathrm{m} . \mathrm{K})]}\end{array}$ & 1.1 & 0.34 & 429 & 163 & 210 \\
\hline $\begin{array}{l}\text { Heat } \\
\text { capacity at } \\
\text { constant } \\
\text { pressure } \\
{[\mathrm{J} /(\mathrm{kg} . \mathrm{K})]}\end{array}$ & 480 & 480 & 235 & 0.703 & 900 \\
\hline $\begin{array}{l}\text { Electrical } \\
\text { conductivity } \\
{[\mathrm{S} / \mathrm{m}]}\end{array}$ & $\begin{array}{l}1 \mathrm{e}- \\
14\end{array}$ & $*$ & $6.16 \mathrm{e} 7$ & $1 \mathrm{e}-12$ & $3.5 \mathrm{e} 7$ \\
\hline $\begin{array}{l}\text { Relative } \\
\text { permittivity }\end{array}$ & 4.2 & $*$ & 11.7 & 11.7 & 10 \\
\hline $\begin{array}{l}\text { Refractive } \\
\text { index }\end{array}$ & 1.5 & 1.5 & $*$ & 3.45 & $*$ \\
\hline Emissivity & $*$ & $*$ & 0.01 & 0.84 & $*$ \\
\hline
\end{tabular}

\subsection{Physics selection and boundary conditions}

The physics selection determines what parameters are solved for and the physical boundaries of the simulation. Two physics interfaces, joule heating and heat transfer in solids with surface-to-surface radiation and radiation in participating media activated are used in the simulation in this study. COMSOL allows for the full coupling of the different physics interfaces. The physical boundaries are also defined for each simulation according to real values and conditions. 


\subsection{Meshing}

The structured mesh type "swept mesh" is used in meshing all the models. The swept mesher operates on a 3D domain by meshing a source face. The source face is meshed with free triangular elements and then the resulting face mesh is swept along the domain to an opposite destination face. A swept mesh is structured in the sweep direction and can be either structured or unstructured orthogonally to the sweep direction

The mesh size is chosen from one of the predefined mesh sizes under general physics. The predefined sizes start from extremely coarse mesh size to extremely fine mesh size. The model is meshed with coarse size mesh. The mesh is made finer at the narrow regions like in the finger, busbar areas and edges and much coarser in the wider regions as shown in Fig -8 .

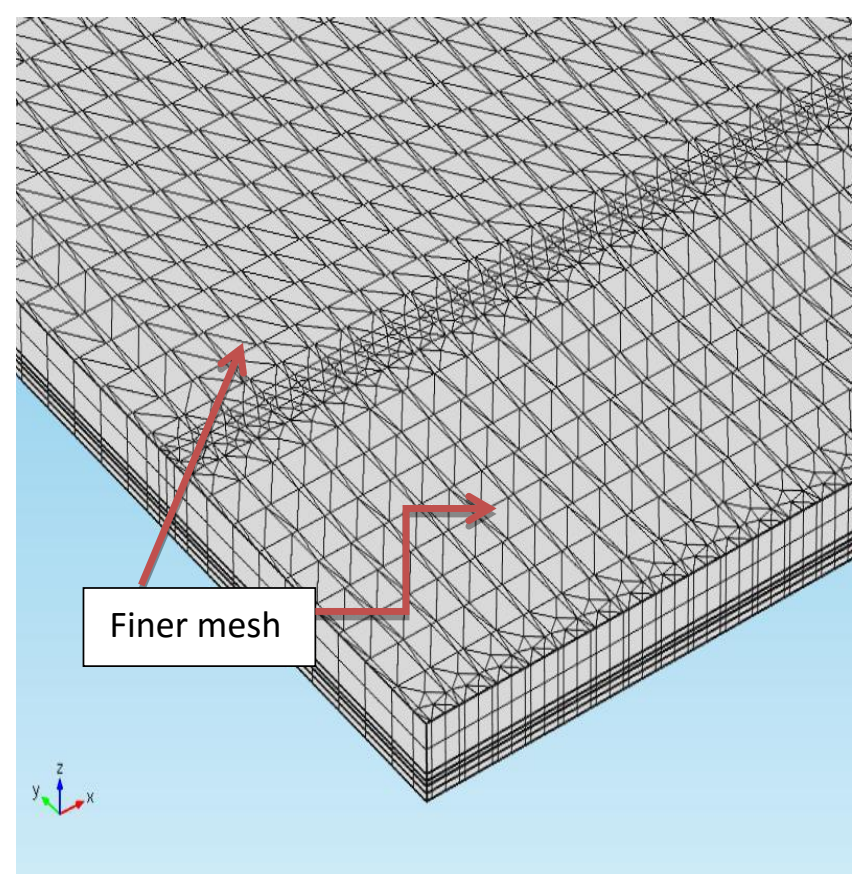

Fig -8: Fine mesh at narrow regions and edges

\subsection{Simulation approach}

The models for the simulations were created as explained in detail in 2.1.1 to 2.1.4. First of all, the models are verified incorporating standard (common) operating conditions where the outcome can be speculated based on literature and experience. Once the initial model was verified to be working properly, further modifications are made to investigate material and atmospheric conditions dependencies.

The simulations are done at the Normal Operating Cell Temperature (NOCT), which is defined as the temperature reached by open circuited cells in a module under the following conditions:

Irradiance on cell surface $=800 \mathrm{~W} / \mathrm{m}^{2}$

Ambient air temperature $=20^{\circ} \mathrm{C}$

Wind velocity $=1 \mathrm{~m} / \mathrm{s}$

Mounting $=$ open back side.
The segregated solver makes it possible to split the solution process into substeps. Each substep uses a damped version of Newton's method. It can be used for both stationary and time dependent solvers. Each subset can have its own solver settings. This solver is made use in simulations of Models B through $\mathrm{D}$ in combination with a direct solver PARDISO. The order in which the segregated steps run can be changed.

\section{RESULTS AND DISCUSSION}

\subsection{Combined effect of Joule heating and solar} irradiance on temperature

COMSOL Multiphysics allows for the metaphysical analysis of modeled systems. The temperature characteristic of the solar cell is dominated by both solar irradiance and Joule heating. These physical effects can be modeled individually and as a combined effect. Table -2 shows the temperature difference in the case of applying solar irradiance only, Joule heating effect only and the combination of both, at the NOCT conditions. The simulations demonstrate that the Joule heating effect produces a small heating of the cell with respect to solar irradiance, as expected. The values of the third column of Table - 2 affirm that the modeled solar cell shows a quasilinear behavior (superposition effect of the two physical effects). The combined effect leads to a slight lower temperature increase as the discrete addition of both effects due to the dependence of heat transfer coefficient on temperature difference. The simple addition of the simulation outcome from individual application of the two physical effects is slightly higher than that from the combined effect simulation. The simple addition of the two physical effects is as shown in Chart -1 by a green line and it is the addition of the blue and magenta lines. The wind speed is varied over a range for each of the three cases and the results are shown in Chart -1 . This behavior is also reported in [9].

Table -2: NOCT results of the solar cell under the three cases (irradiance, Joule heating and a combination of both). $\mathrm{Ta}=$ Ambient Temperature, $\mathrm{Tc}=$ Max. Cell Temperature, $\Delta \mathrm{T}=$ Temperature difference

\begin{tabular}{|l|l|l|l|}
\hline & Ta $\left({ }^{\circ} \mathbf{C}\right)$ & $\begin{array}{l}\text { Tc } \\
\left({ }^{\circ} \mathbf{C}\right)\end{array}$ & $\mathbf{\Delta T}\left({ }^{\circ} \mathbf{C}\right)$ \\
\hline Solar irradiance & 20 & 44.102 & 24.102 \\
\hline Joule heating effect & 20 & 22.74 & 2.74 \\
\hline $\begin{array}{l}\text { Solar irradiance } \\
\text { and Joule heating } \\
\text { effect }\end{array}$ & 20 & 46.05 & 26.05 \\
\hline
\end{tabular}

The confirmation of the existence of the relationship between the individual physical effects applied alone and as a combine effect lead to the decision to simulate in most cases the irradiance physical effect only. This was done 
because of memory constraints and computational cost. The Joule heating effect is constant for a given current density and its effect on overall cell/module temperature is proven to be minimal.

Due to the accumulation of the generated current in one direction to be connected to external load or the adjacent cell, there is more current in the busbar towards one end and that end turns to heat up more. The surface temperature color maps belonging to the three cases reported in Table -2 is shown in Fig -10. This also highlights the current accumulation effect in the Joule heating model.

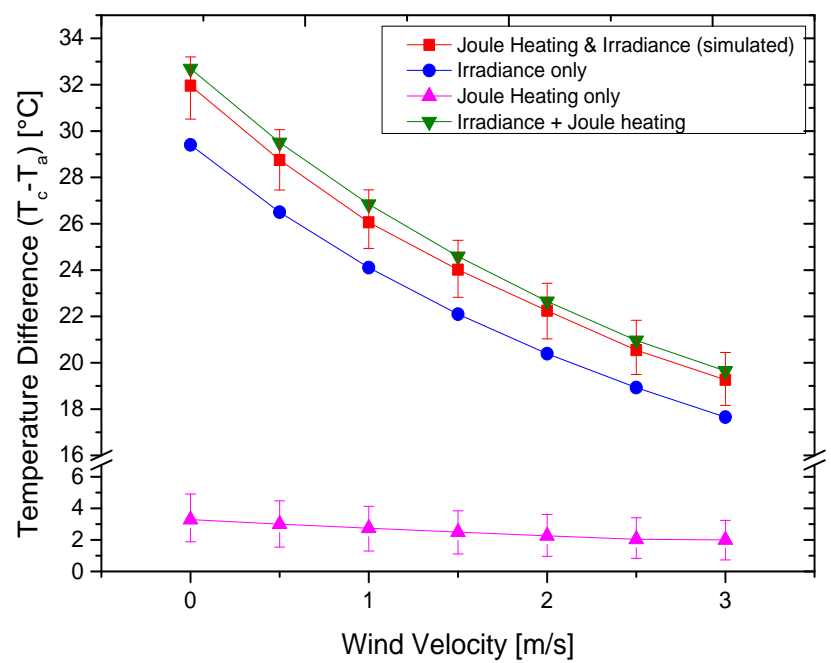

Chart -1: Superposition effect of solar irradiance and Joule heating. The Joule heating effect causes temperature difference across the cell. The average cell temperature is plotted and the error bars used to show the deviation from maximum and minimum temperatures.

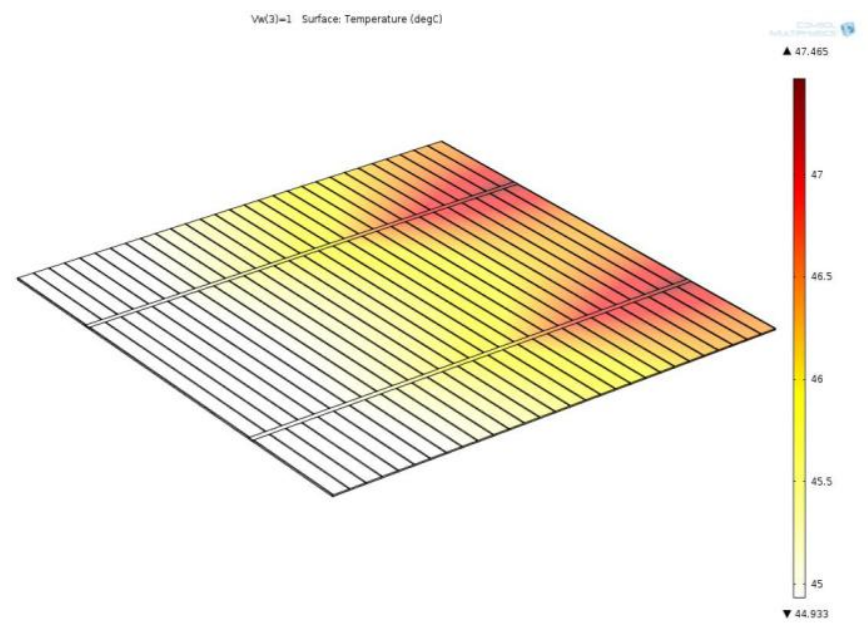

Fig -10: Temperature map of combined effect of Joule heating and solar irradiance

\subsection{Effect of Encapsulation Material On Cell}

\section{Temperature}

Chart -2 shows the temperature of the cell without encapsulation plotted with the ones encapsulated with EVA and silicone. The cell was subject to a solar irradiance of
$800 \mathrm{~W} / \mathrm{m}^{2}$ and the wind velocity on both sides varied from 0 $\mathrm{m} / \mathrm{s}$ to $3 \mathrm{~m} / \mathrm{s}$. There is a clear rise in the temperature due to encapsulation but not a significant difference when the EVA or silicone is used.

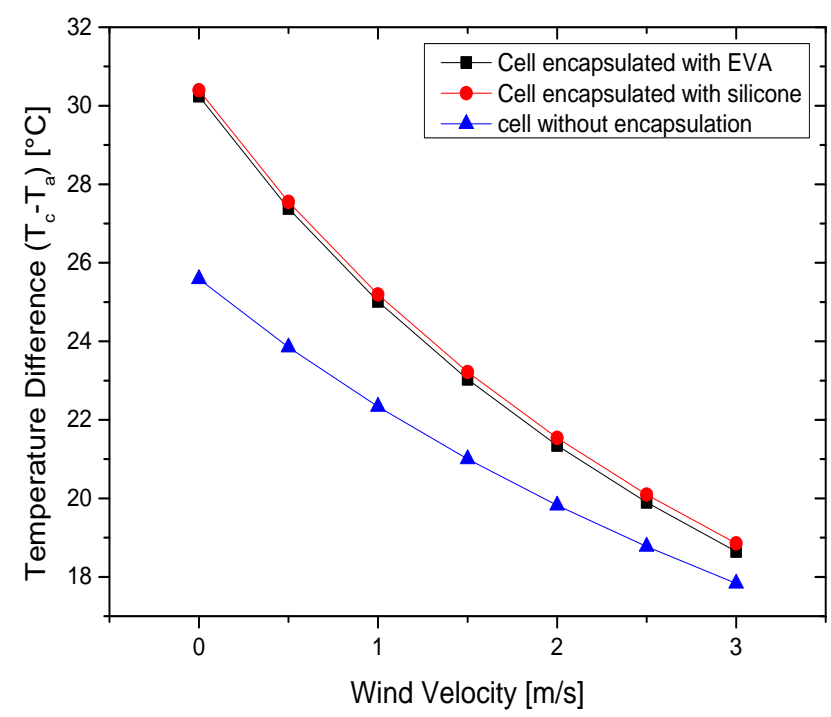

Chart -2: Effect of encapsulating materials EVA and silicone on cell temperature

The color map for the NOCT condition using EVA as the encapsulating material is also given in Fig -11. The module has the highest temperature at the cell and the lowest at the top of the protective glass cover. The temperature difference between cell and glass surface is about $1^{\circ} \mathrm{C}$ in all simulations.

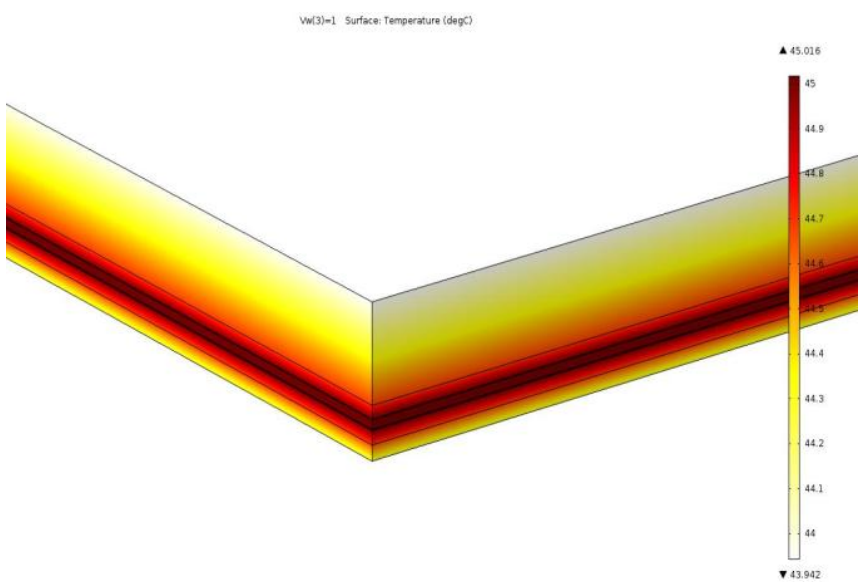

Fig -11: Surface temperature map of EVA encapsulated solar cell at NOCT conditions

\subsection{Effect of Copper Interconnection On Module}

\section{Temperature}

In forming a module, two or more solar cells are placed approximately $7 \mathrm{~mm}$ apart in series, electrically connected with copper ribbons and then encapsulated. The modeling of a solar module is given in 2.1.4 as Model D. This mini module was simulated using the same conditions of 800 $\mathrm{W} / \mathrm{m}^{2}$ irradiance, $20^{\circ} \mathrm{C}$ ambient temperature and the wind velocity varying from $0 \mathrm{~m} / \mathrm{s}$ to $3 \mathrm{~m} / \mathrm{s}$ as was used for Model 
B. The result from 3.2 is presented here in Chart -3 to include the result of simulating the mini module with copper ribbon interconnection. The resulting plot shows that, connecting solar cells with copper ribbons and encapsulating it into a module actually decreases the cell temperature. Even though the cell temperature is still above that of the cell without encapsulation the decrease in cell temperature of the mini module is significant as can be seen in Chart -3 .

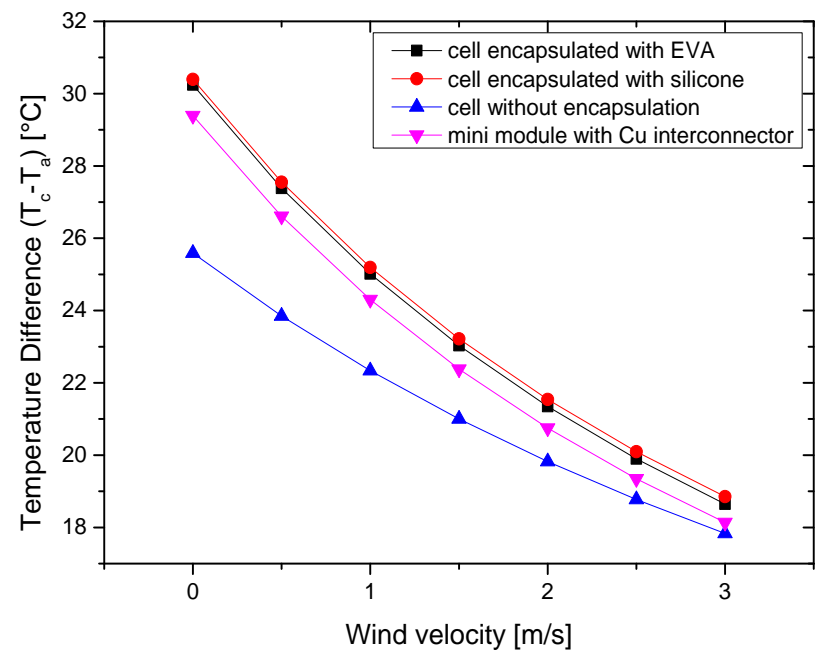

Chart-3: Reduction in cell temperature in the mini module compared to a single cell

Copper being a good conductor absorbs more heat. The copper ribbon interconnections are totally surrounded by EVA which turns to conduct most of the heat away from the copper interconnections. Therefore, the copper interconnections do not show any strong contribution in terms of raising the cell temperature. The region of the mini module where the gap between the two adjacent cells and the copper interconnection is located turns out to have the lowest temperature. The distribution of the temperature in this area and that in the EVA filling the area around the copper ribbon interconnections is best seen in a $2 \mathrm{D}$ isosurface temperature map shown in Fig -12.

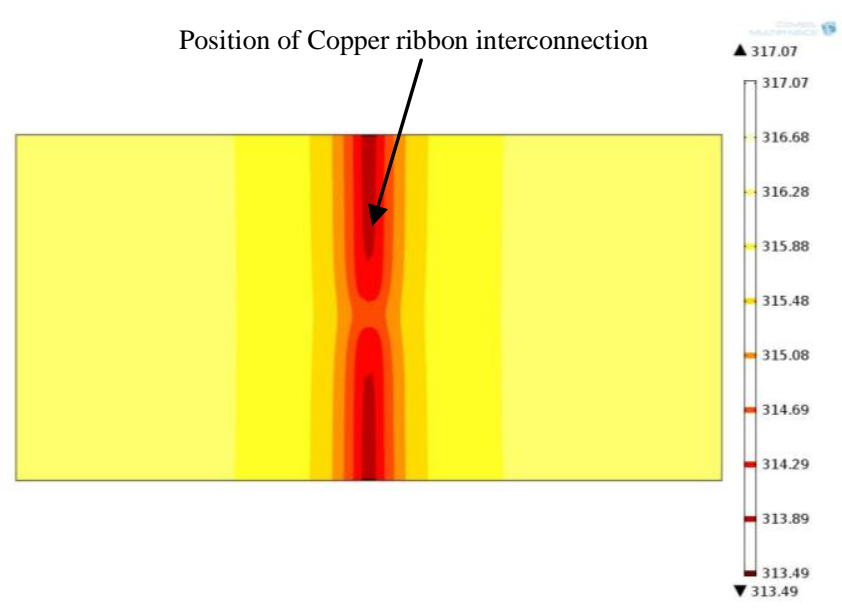

Fig -12: 2D Isosurface temperature map showing the temperature distribution in the mini module and around the copper stripe

\section{CONCLUSIONS}

In this study, the temperature reached by solar cells/modules during operation and also information about the temperature distribution in the solar cell/module is provided by utilizing a finite element (FE) model of the solar cell/module which has been created in COMSOL Multiphysics environment. Four different geometries (models) of the solar cell/module were created for these simulations; each represented a stage in the solar module manufacture or a variant.

The models have been verified by checking for the variation in temperature due to changes in solar irradiance, wind speed and solar irradiance angle of incident. They showed good conformance with the values from literature and experience.

Two major contributors as source of heat for the solar module have been identified as solar irradiance and Joule's heating effect. Joule's heating effect contributes much less compared to solar irradiance and the two effects are shown to have quasi-linear behavior when simulated together. This allowed for the dropping of the Joule heating effect in the more complex simulation where memory usage was of concern. The cell/module temperature maps obtained are corrected with that from the Joule heating only simulation which is constant for a given current density.

The subject of encapsulation has been shown to be very important for the life time of the cell and its electrical parts. The encapsulants used to protect the solar cell are responsible for about $11 \%$ increase in the cell temperature at NOCT conditions. EVA and silicone are the most used encapsulants with silicone giving the highest efficiency due to its low absorptivity compared to EVA but is more expensive. There was negligibly small increase in temperature of silicone encapsulated cells compared with those with EVA.

Protecting the front of the solar module with glass and the rear with Tedlar compared to protecting it on both sides with glass revealed no significant change in temperature. Solar modules protected by glass on both sides have a slightly higher temperature due to the thickness of the glass used. The thickness of glass used in a module is not much of thermal concern but more of structural.

Two or more cells electrically connected together via copper ribbons and encapsulated into a module has been simulated to have a lower temperature than a single cell module due to the distance between the adjacent cells and the copper ribbon interconnection not contributing to an increase in cell temperature. The temperature in the module increases beginning from the middle of the mini module where the copper ribbons surrounded by EVA are. The temperature increases towards the edges of the module in the horizontal plane but the solar cell itself has a uniform temperature distribution, though with a lower average temperature. 


\section{REFERENCES}

[1]. C. Honsberg and S. Bowden, "Module Materials," http://www.pveducation.org/pvcdrom/modules/module -materials

[2]. T. Hausler and H. Rogass, " Latent heat storage on photovoltaic," in Sixteenth European Photovoltaic Solar Energy Conference, , Glasgow, UK, 2000:22652267.

[3]. Vignola, "Solar Cells," University of Oregon Solar Radiation Monitering Lab, 2000.

[4]. National Renewable Energy Lab, "Spectrum Definition for information, data and resources for solar".

[5]. AZoM.com, "Silicone Rubber material," www.grantadesign.com.

[6]. MathWeb, "Material property data," http://matweb.com/search/PropertySearch.aspx.

[7]. P. Industries, "Solarphire Glasses by PPG," PPG Glass Business \& Discovery Center: http://www.ppg.com/en/solutionbyindustry/energy/sola r/Pages/default.aspx, Cheswick, PA 15024 .

[8]. COMSOL, "Comsol Material Library," COMSOL.

[9]. S. Vergura, G. Acciani and O. Falcone, "3-D PV-cell Model by means of FEM," IEEE, Bari, Italy, 2009. 